\title{
Electrical load forecasting
}

\author{
S. A. Eroshenko ${ }^{1}$, K. V. Vinokurov ${ }^{2} \&$ A. Y. Smolina ${ }^{2}$ \\ ${ }^{1}$ Ural Federal University, Russia \\ ${ }^{2}$ Federal Grid Company of Unified Energy System JSC, \\ Backbone Electric Grids of Ural (MES Ural), Russia
}

\begin{abstract}
Some long-term design activities are based on electrical load forecasting. Forecasting errors result in the wrong decisions being made in the future. At present there are three widely used methods of forecasting: the method based on enlarged specific indexes (ESI), the econometric method and the self-sufficient method. All of these methods have their own disadvantages and errors in estimation.

The main reasons for errors in areas such as objective reasoning, changes in production technology, the lack of reliable long-term forecasting for economy development and consumer infraction of load schedule are determined in this paper and an objective estimation for the forecasted error of different spheres of application is made. This work aims to determine a sphere of application for each of these methods and to develop a principal of combined application, so that they may decrease forecasting error.

The purpose of this work consists of the creation of an electrical load forecasting method to obtain more reliable data for the different time periods and territory.
\end{abstract}

A new method is presented, based on calculations carried out. Recommendations for all existing methods are given with reference to the calculations and the way that the combined application of several methods was introduced to increase the reliability of a forecast.

Keywords: electric load, electricity demand forecasting.

\section{Introduction}

Electric power load and electricity demand forecasting are the most important tasks of electricity engineering. Accurate analysis of such points lets us determine the conditions for sustainable energy supplement [1]. 
Forecasting of electrical loads is essential for the Federal Grid Company because it provides optimal development of a unified national electrical grid. This is necessary to satisfy power demands and meet consumer needs in electrical energy during the period under investigation and so as to plan for only the objects that are demanded [2].

According to methodical recommendations for the design of energy systems development [3] there are three methods of electric power load and electricity demand forecasting: the method based on enlarged specific indexes (ESI), the econometric method and the self-sufficient method.

The ESI method is based on knowledge of the electrical capacity of economical branches and sectors that make the greatest impact on energy consumption during the period of a survey. Prediction for the period under investigation is made by multiplying the known electrical capacity and for economical branches. Then the actions that can influence electrical capacity are taken into consideration.

\section{Method analysis}

The following is an analysis of these three methods.

\subsection{ESI method}

During analysis of the ESI method the following problems were indicated:

1. The electrical capacity of production changes.

2. There are no reliable prediction indexes for economical branch development

Energy consumption of enterprises consists of two parts: a constant part and a variable part. The variable part depends on production output, whereas the constant part does not. Thus, due to the fact of dividing the total electricity consumption by the production output without isolation of the constant part an error is introduced in the determination of the electrical capacity of the production output.

For the utilities sphere and the services sector, electrical capacity is calculated by dividing the energy consumption by the population. However, another trend is viewed. The population is decreasing, but electricity consumption is growing due to the improvement in the standard of living.

Besides the error in electrical capacity determination, there is an additional error caused by changing of technologies. Table 1 shows the specific energy consumption for different types of production and plant. The data was provided by GosComStat.

According to Table 2, the change in separate production types reaches $126 \%$. Collecting of relevant information about predicted production output is a difficult task. Often large companies don't announce their plans and furthermore they can abort agreed investment plans. Besides this reasons, production output greatly depends on market conjuncture.

This method can be applied to large territories (EES, OES), because local errors in production output can be neglected due to the scale effect. 
Table 1: Specific electrical consumption for different types of production and plant $(\mathrm{kWh} / \mathrm{tn})$.

\begin{tabular}{|l|c|c|c|c|c|c|c|}
\hline \multicolumn{1}{|c|}{ Types of production } & $\mathbf{1 9 9 5}$ & $\mathbf{2 0 0 0}$ & $\mathbf{2 0 0 5}$ & $\mathbf{2 0 0 6}$ & $\mathbf{2 0 0 7}$ & $\mathbf{2 0 0 8}$ & $\mathbf{2 0 0 9}$ \\
\hline Coal Mining & 36.2 & 26.8 & 22.9 & 22.7 & 21.2 & 20 & 20.4 \\
\hline $\begin{array}{l}\text { Crude oil and gas } \\
\text { concentrate }\end{array}$ & 102.9 & 98.6 & 104.3 & 107.9 & 123.4 & 127.4 & 122.7 \\
\hline Bread and bakery & 103 & 189 & 202 & 203 & 230 & 212 & 233 \\
\hline Paper & 810 & 1144 & 1113 & 1093 & 1068 & 1054 & 1016 \\
\hline $\begin{array}{l}\text { Oil and gas } \\
\text { concentrate } \\
\text { processing }\end{array}$ & 51.8 & 49.9 & 46.6 & 46.4 & 46 & 46.4 & 46.9 \\
\hline Synthetic rubber & 2945 & 2971 & 2700 & 2531 & 2166 & 2543 & 2659 \\
\hline Cement & 132 & 139 & 135 & 113 & 113 & 111 & 108 \\
\hline $\begin{array}{l}\text { Electrical Metallurgy } \\
\text { Steel }\end{array}$ & 781.5 & 714.1 & 631.7 & 564.7 & 535.1 & 537.4 & 552.6 \\
\hline Ferrous metals rolling & 168.6 & 151.7 & 139 & 137.5 & 138.9 & 129 & 121.4 \\
\hline $\begin{array}{l}\text { Electrical Metallurgy } \\
\text { Ferroalloys }\end{array}$ & 5268 & 5791 & 5348 & 5375 & 5337 & 5119 & 5154 \\
\hline
\end{tabular}

Table 2: Electrical capacity of the production changes.

\begin{tabular}{|l|c|}
\hline \multicolumn{1}{|c|}{ Types of production } & \% change \\
\hline Coal Mining & 81 \\
\hline Crude oil and gas concentrate & 29 \\
\hline Bread and bakery & 126 \\
\hline Paper & 41 \\
\hline Oil and gas concentrate processing & 13 \\
\hline Synthetic rubber & 37 \\
\hline Cement & 29 \\
\hline Electrical Metallurgy Steel & 46 \\
\hline Ferrous metals rolling & 39 \\
\hline Electrical Metallurgy Ferroalloys & 13 \\
\hline
\end{tabular}

\subsection{Econometrical method}

Obviously, nowadays electrical consumption truly shows the economical development in Russia and its regions.

During the comparison of electrical consumption and Russian GDP as well as the comparison of electrical consumption and GRP of regions of Russia a very high correlation was found. Figure 1 shows the electrical consumption and Russian GDP.

As for UES Russia, the correlation during the period 1995-2007 was about 0.994 (GDP is given in comparable prices).

The main source for error in that method is the inaccuracy of economical prediction. Thus we can conclude that the econometrical method creates a large error in critical economical moments. 
Using that method we can predict general trends, but it is difficult to say in at point increase of the electrical load will appear.

This method can be used for large territories (UES, OES) to determine the total generating power, which is needed to satisfy the forecasted electrical energy demand.

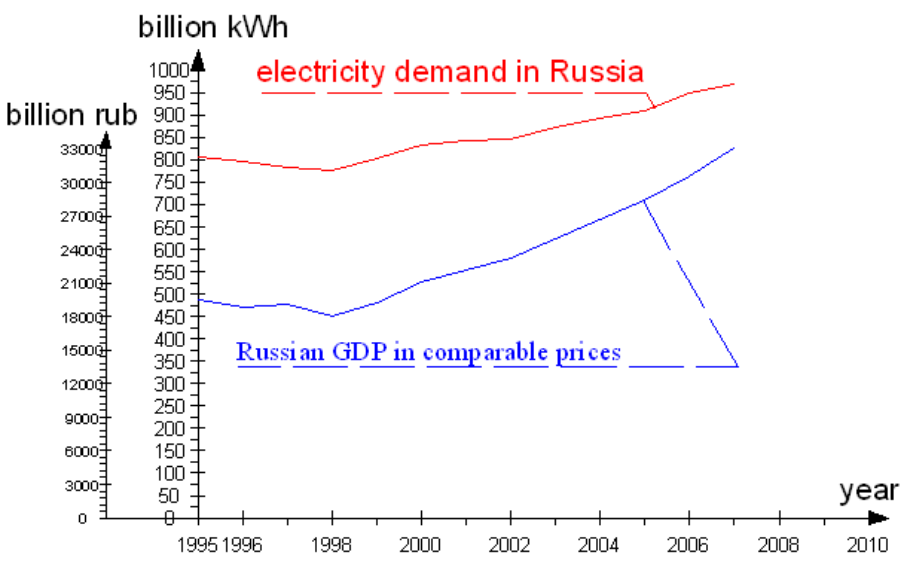

Figure 1: Electrical consumption and Russian GDP.

\subsection{Self-sufficient method}

In practice this method gives an error of about $5 \%$ in the case of predictions of up to 5 years. This method is suitable for territories of any scale. The major problem of this method is the maximum prediction length of 5 years.

Requests are the source of the error. Growth of electrical load and electrical consumption are being determined according to connection requests. This growth is usually overvalued because new enterprises don't consume the rated power from the very beginning. Furthermore, requests from large consumers who are already connected contain errors too.

\subsection{Summary}

If we use both the ESI method and the econometric method, we can get a forecast for a long period of time for large territories (UES, OES).

The self-sufficient method gives good results if we use it for predictions of up to three years. The maximum length of forecasting made with the self-sufficient method is 5 years because we cannot get any information about further plans.

\section{Complex method}

The complex method is a self-sufficient method that is integrated with the econometric method.

We will now discuss an example based on electrical consumption requests made by "VSMPO-AVISMA Corp" and the JSC "Chusovkoy Metallurgy Plant" 
(CMP). According to the National Classification of Economic Activities, both of these enterprises are the "metallurgy production and production of ready metal parts"; both are based in the Perm region but they have different types of production. VSMPO-AVISMA is nonferrous metallurgy, CMP is ferrous metallurgy.

Table 3 shows the electrical consumption forecast made according to requests from both of those plants at the beginning of 2009. Table 4 shows the real electrical energy consumption for both enterprises.

Tables 3 and 4 show that there are significant errors made in the requests. Figure 2 demonstrates the errors in the requests. We now analyze how it correlates with the economical indexes for the Perm region. Table 5 shows the real index for that type of economical activity for the Perm region: the real index of metallurgy production and production of metal products manufacturing.

Table 3: Electrical consumption forecasting made according to requests.

\begin{tabular}{|l|c|c|c|}
\hline \multirow{2}{*}{ Enterprise name } & \multicolumn{3}{|c|}{ Forecasting, million kWh } \\
\cline { 2 - 4 } & $\mathbf{2 0 0 9}$ & $\mathbf{2 0 1 0}$ & $\mathbf{2 0 1 1}$ \\
\hline VSMPO-AVISMA & 1153 & 1225 & 1297 \\
\hline CMP & 316 & 330 & 400 \\
\hline
\end{tabular}

Table 4: Real electrical energy consumption.

\begin{tabular}{|l|c|c|c|c|}
\hline \multirow{2}{*}{ Enterprise name } & \multicolumn{4}{|c|}{ Annual electrical energy consumption, million kWh } \\
\cline { 2 - 5 } & $\mathbf{2 0 0 8}$ & $\mathbf{2 0 0 9}$ & $\mathbf{2 0 1 0}$ & $\mathbf{2 0 1 1}$ \\
\hline VSMPO-AVISMA & 1311.106 & 947.207 & 959.018 & 692.487 \\
\hline CMP & 311.739 & 134.744 & 154.935 & 161.906 \\
\hline
\end{tabular}

VSMPO-AVISMA Corp presents nonferrous metallurgy and Chusovskoy Metallurgy Plant presents ferrous metallurgy.

Looking at Fig. 3, the production index is connected with the energy consumption of the specific consumer, but it influences the energy consumption index of the specific consumer differently.

Thus, if we know the index of economical action for the respective period, we can predict the change in electrical consumption.

As we know, the longer the prediction, the larger the error given.

Economical prediction errors can be clearly shown with the example of Bogoslovskiy Aluminum Plant (BAP). Table 6 shows prediction data that was collected in 2007.

As a result of price falls in the aluminum market the plant became uncompetitive. Today the plant is closing.

According to control measuring at 2012, winter maximum electrical load was 165.1 MW.

Thus, to increase forecasting accuracy we need to decrease the forecasting period. To do this we need to decrease the building time for electrical grid objects. 

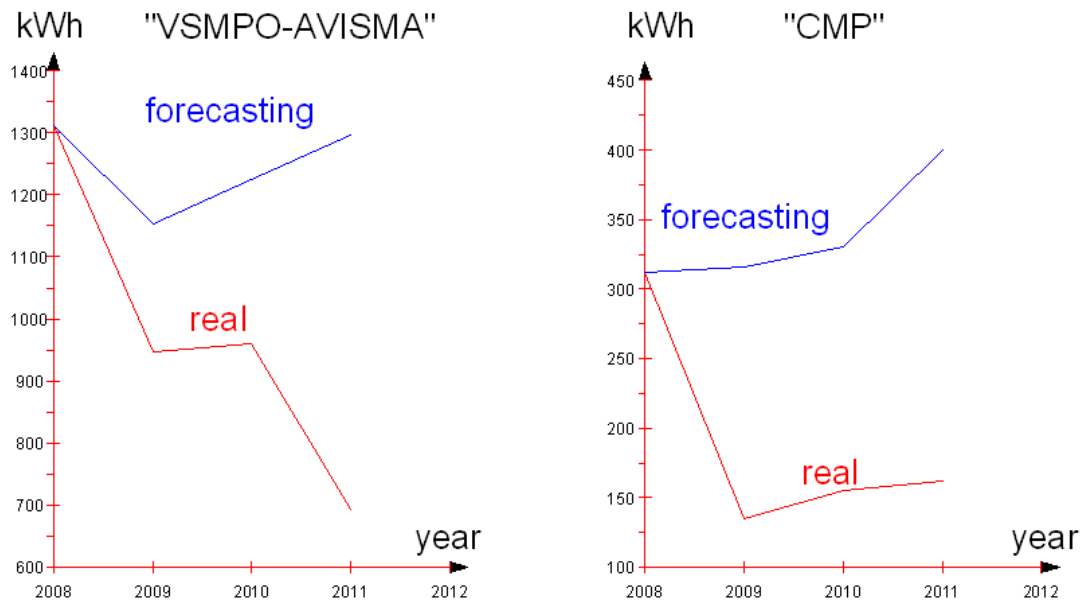

Figure 2: $\quad$ Error in forecasting.

Table 5: The real index of metallurgy production and production of ready metal parts.

\begin{tabular}{|l|c|c|c|c|}
\hline \multirow{2}{*}{ Type of production } & \multicolumn{4}{|c|}{ Real index } \\
\cline { 2 - 5 } & $\mathbf{2 0 0 8}$ & $\mathbf{2 0 0 9}$ & $\mathbf{2 0 1 0}$ & $\mathbf{2 0 1 1}$ \\
\hline $\begin{array}{l}\text { Metallurgy production and production } \\
\text { of ready metal parts }\end{array}$ & 98.9 & 48.3 & 132.3 & 126.1 \\
\hline
\end{tabular}

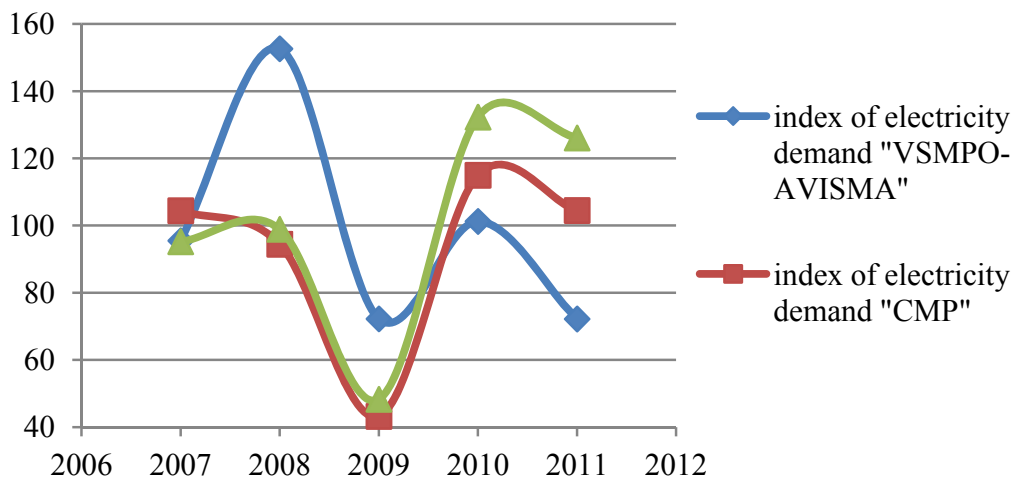

Figure 3: Index of economical action and index of electricity demand.

Table 6: The prediction in 2007.

\begin{tabular}{|c|c|c|c|}
\hline \multirow{2}{*}{ Enterprise } & Report & \multicolumn{2}{|c|}{ Request data } \\
\cline { 2 - 4 } & $\mathbf{2 0 0 5}$ & $\mathbf{2 0 1 0}$ & $\mathbf{2 0 1 5}$ \\
\hline BAP & 440.3 & 650 & 650 \\
\hline
\end{tabular}




\section{Conclusion}

At this moment there are different approaches to the forecasting of electrical loads and electrical consumption. All of them have different problems and features. Energy consumption gives quite accurate data about the economical conditions of the territory of the survey, so we need accurate economical predictions to make accurate electrical consumption forecasts.

Unfortunately in the case of a market economy there cannot be any precise economical forecasts. Both insufficient and excess predictions give negative results.

In this article a complex method is offered. It is based on elaboration of requests with the econometric method. Using a complex method for long forecasts is inefficient because in this case economical predictions do not allow us to increase accuracy.

Long-time electric power load and electricity demand forecasting is needed to build all the necessary objects in time to provide sustainable energy supplies. For example, it takes 6 years minimum to build a $500 \mathrm{kV}$ substation from the moment of making the decision to build it.

Taking into consideration the high level of uncertainty and errors for long periods of time (more than 5 years) we need to work at decreasing building times.

\section{References}

[1] Kokin S.E., Pazderin A.V., Adarichev E.N., Ways of decreasing maximum and equalizing curve of big cities' power demand, 1st International Conference on Sustainable Power Generation and Supply, SUPERGEN '09, 6-7 April, 2009, Nanjing, China, art. no. 5347879.

[2] Khalyasmaa A.I., Dmitriev S.A., Kokin S.E., Energy information model for power systems monitoring, 2013 2nd International Conference on Energy and Environmental Protection, ICEEP 2013; 19-21 April 2013, Guilin; China, Code 99790.

[3] Methodical recommendations for designing of energy systems CO 153-34.20.118-2003, 2003, 26 p. (in Russian).

[4] Reference design power systems. Ed. Rokotyana, S.S., Shapiro, I.M., Energoatomizdat, 1985, p. 352 (in Russian). 